\title{
Simulation of Two-stage Automotive Shredder Residue Pyrolysis and Gasification Process Using the Aspen Plus Model
}

\author{
Bin Yang and Ming Chen *
}

The disposal of automotive shredder residue (ASR) directly affects China's goal of achieving a 95\% recycling rate for end-of-life vehicles. Pyrolysis and gasification have gradually become the most commonly used thermochemical technologies for ASR recycling. To obtain more hydrogen-rich syngas, it is necessary to determine the optimal process parameters of the ASR pyrolysis and gasification process. The main process parameters of the two-stage ASR pyrolysis and gasification process were studied using the established Aspen Plus model. Through analyzing the effects of process parameters, such as the temperature, equivalence ratio, and mass ratio of steam to ASR feedstock, on the product distribution and product characteristics of ASR pyrolysis and gasification, the optimal process parameters were determined. A series of comparative experiments under different conditions were conducted. The experimental results verified the accuracy and reliability of the Aspen Plus simulation model for the ASR pyrolysis and gasification processes and verified the practical feasibility of the process parameters obtained from the simulation analysis.

Keywords: Automotive shredder residue; Pyrolysis; Gasification; Aspen Plus; End-of-life vehicle

Contact information: School of Mechanical Engineering, Shanghai Jiao Tong University, No. 800, Dongchuan Rd., Shanghai 200240, China; *Corresponding author: mingchen@sjtu.edu.cn

\section{INTRODUCTION}

Vehicle ownership in China has increased rapidly in the last two decades, with the number of civil cars reaching 260 million at the end of 2019. With the development of the social economy and changes in the consumption concept, the service time of automobiles has become increasingly shorter, which has led to a rapid growth in the number of end-oflife vehicles (ELVs). Soil pollution, water pollution, and resource waste easily occur if ELVs are not recycled properly. Therefore, the recycling and recovery of ELVs has attracted much attention. Various countries or regions have also promulgated relevant laws and regulations, which stipulate the target recycling rate of ELVs (Chen and Zhang 2009; Wang and Chen 2013). In the future, China will adopt large-scale mechanized equipment for dismantling, crushing, and sorting to recycle ELVs, which will inevitably produce a large amount of automobile shredder residue (ASR). At the end of its useful life, a car is processed by the dismantling and recycling company. The engine, fuel tank, seat, car glass, car computer, car lights, airbag, etc., are all removed. The remaining part is compressed into blocks. The crushing and sorting company purchases these blocks and sends them to the crusher. Then, the iron and non-ferrous metals are sorted out using techniques such as magnetic separation and eddy current separation. The remaining part is the automotive shredder residue (ASR). Automobile shredder residue accounts for 20 to $25 \%$ of an ELV 
by weight (Ahmed et al. 2014; Ruffino et al. 2014; Cossu and Lai 2015), and the disposal of ASR directly affects China's goal of achieving a 95\% recycling rate of ELVs. With the development of new materials and the promotion of auto-lightweight technologies, organic materials are more widely used in automobiles. Thus, an increasing number of organic components appear in the ASR, which contribute to approximately 60 to $85 \%$ of the ASR weight, i.e., 20 to $55 \%$ plastic, 5 to $36 \%$ textiles, 2 to $20 \%$ rubber, and 3 to $11 \%$ foam (Fiore et al. 2012; Passarini et al. 2012; Cossu et al. 2014). Bioenergy contained in organic waste is expected to become one of the major energy resources in the future because it is renewable and free from net carbon dioxide emissions. Therefore, converting ASR into bioenergy through thermochemical technologies will greatly alleviate the increasingly serious energy crisis.

Pyrolysis and gasification have gradually become the most commonly used thermochemical technologies for ASR recycling, because these methods can reduce the volume and quality of landfills at a lower cost, while energy recovery can also be simultaneously performed (Lin et al. 2010; Mancini et al. 2010; Vermeulen et al. 2011). Gaseous products of ASR pyrolysis and gasification can be utilized as fuel gas or raw chemicals in polymer generation or in the production of value-added chemicals. Gaseous products with high calorific values mainly consist of $\mathrm{H}_{2}, \mathrm{CO}, \mathrm{CH}_{4}, \mathrm{C}_{2} \mathrm{H}_{4}, \mathrm{C}_{2} \mathrm{H}_{6}, \mathrm{C}_{3} \mathrm{H}_{6}$, and $\mathrm{C}_{3} \mathrm{H}$. Syngas can be further enriched in its hydrogen concentration by capturing carbon dioxide, by use of suitable sorbents. Hydrogen has the potential to be a replacement for conventional fuels, being a clean fuel with a higher energy density on a mass basis. The purpose of this project was to obtain more hydrogen-rich syngas by optimizing the pyrolysis and gasification process. With ASR as the feedstock, the fraction yields can be controlled by varying the reaction conditions. Fast pyrolysis maximizes the liquid yield, while slow pyrolysis achieves high char yields. De Filippis et al. (2003) established a bench-scale two-stage reactor for gasifying ASR and investigated its efficiency in obtaining syngas and the gas composition based on the mass and energy balances, as well as the chemical equilibrium.

Aspen Plus (Aspen Technology, Inc., Bedford, MA, USA) is a problem-oriented process simulation program that is often exploited to model chemical processes that involve solid, liquid, and gaseous streams under defined conditions by using mass and energy balance equations and a phase equilibrium database. Over the years, Aspen Plus has made model creation and upgrading easier, where small sections of complex and integrated systems can be created and tested as separate modules before they are integrated. Realistic and reliable simulation analyses can provide valuable insights to supplement experimental studies, and it can considerably reduce the time and investment involved in exploring the optimal process conditions for pyrolysis and gasification processes. Aspen Plus has been used by many researchers for designing and optimizing pyrolysis and gasification processes. Aspen Plus is favored by researchers to simulate biomass pyrolysis and gasification (Doherty et al. 2009; Paviet et al. 2009; Abdelouahed et al. 2012; Fu et al. 2012; Rafati et al. 2015; Pauls et al. 2016; Gagliano et al. 2017; Humbird et al. 2017; Liu et al. 2017; Pala et al. 2017; Peters et al. 2017; Lan et al. 2018). In these studies, the influence of parameters on the characterization of gaseous products is often considered, such as equivalent ratios (ER) (Li et al. 2012), temperature, mass ratio of steam to materials, etc. Aspen Plus simulation of municipal solid waste gasification also has been conducted to evaluate the effects of the air equivalence ratio, moisture concentration, and gasifier temperature on the lower heating value (LHV) of syngas, the composition of syngas, heat conversion efficiency, and carbon conversion of municipal solid waste (Chen 
et al. 2010; Niu et al. 2013; Chen et al. 2013; Begum et al. 2014; Deng et al. 2019; Tavares et al. 2019; Tungalag et al. 2020). In short, the role of Aspen Plus software in the pyrolysis and gasification process simulation research has become well established. Therefore, this paper will also use Aspen Plus to establish the simulation model of the two-stage ASR pyrolysis and gasification process. Based on the established Aspen Plus simulation model, the influence of different process parameters on the gas products in the ASR pyrolysis and gasification process will be analyzed. Compared with the experimental results of laboratory-scale two-stage ASR pyrolysis and gasification experiments, the accuracy and reliability of the established Aspen Plus simulation model will be verified.

\section{EXPERIMENTAL}

\section{Simulation Model of the ASR Pyrolysis and Gasification Process}

According to the research works of the ASR pyrolysis, a simulation model of the two-stage ASR pyrolysis and gasification process was designed and established in Aspen Plus V8.4 (Aspen Technology, Inc., Bedford, MA, USA), as shown in Fig. 1.

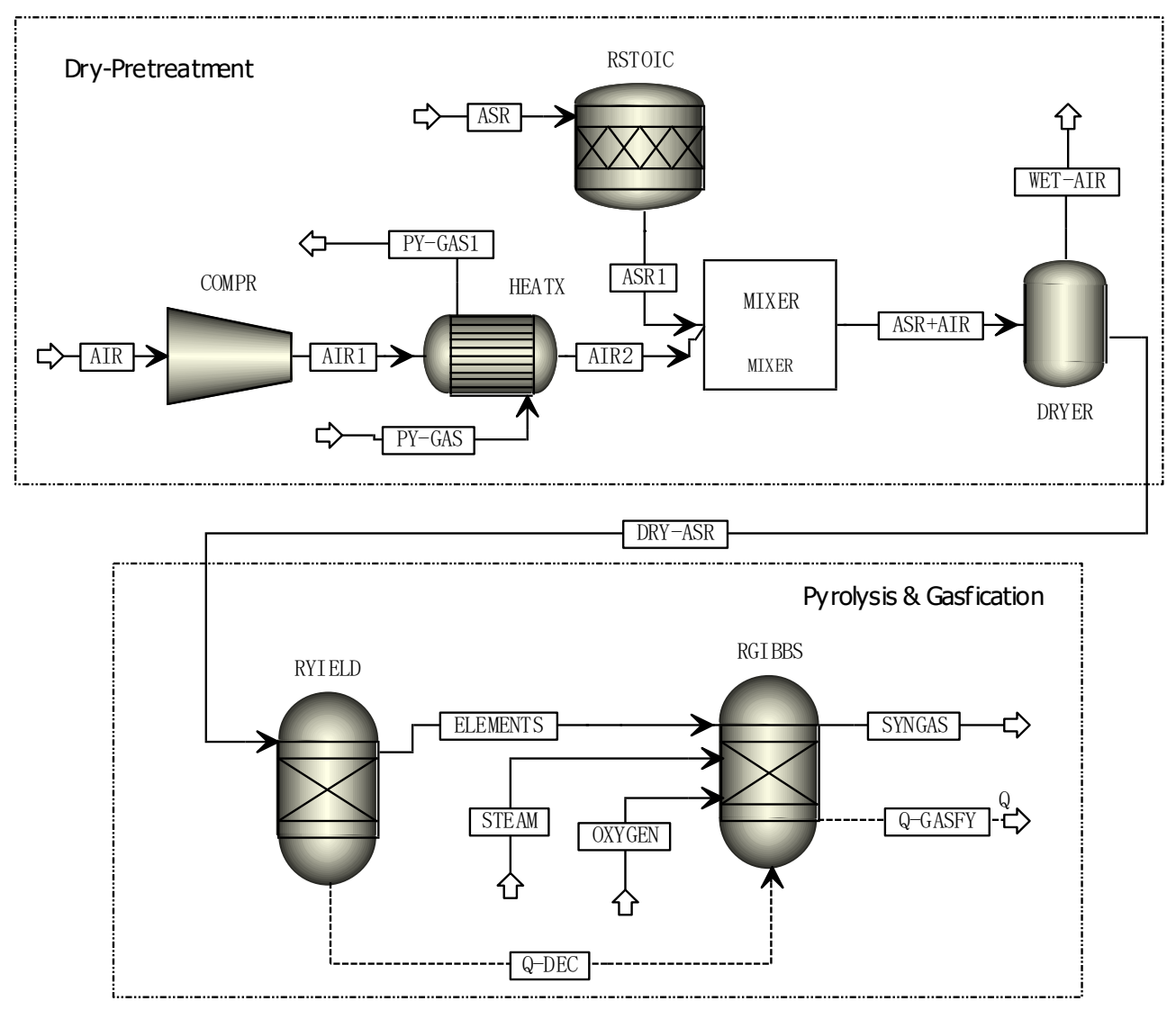

Fig. 1. Aspen Plus simulation flow sheet of ASR pyrolysis and gasification

In the simulation model, ASR is defined as an unconventional solid. The input stream is simulated according to the results of the element analysis and industrial analysis of ASR. Automobile shredder residue successively enters the drying module, pyrolysis module, and gasification module. The description of each module is shown in Table 1 . The 
simulation model follows the mass balance, energy balance, and chemical equilibrium. The mass balance is mainly set by the conservation of the mass flow rate of each element in the model's import and export streams. Chemical equilibrium refers to the dynamic equilibrium state in the pyrolysis gasification reaction process, which is mainly determined by the reaction's raw materials, the product concentration, and the reaction's temperature and pressure. Energy balance refers to the total energy conservation at the inlet and outlet of the model.

Table 1. Introduction of Block Units in the Aspen Plus Simulation Flow Sheet

\begin{tabular}{|c|c|}
\hline Reactor Block & Description \\
\hline COMPR & $\begin{array}{c}\text { When the pressure, power, or characteristic curve is known, the reactor can } \\
\text { change the flow pressure. }\end{array}$ \\
\hline DRYER & Reactor where materials are dried at a set temperature \\
\hline HEATX & Reactor simulating heat exchange between two streams \\
\hline MIXER & Reactor used to mix multiple streams into one stream \\
\hline RGIBBS & $\begin{array}{l}\text { Reactor with a single-phase chemical equilibrium, or simultaneous phase } \\
\text { and chemical equilibrium by minimizing the Gibbs free energy, subject to } \\
\text { atom balance constraints. This reactor is useful for calculating the } \\
\text { equilibrium for solid solutions and gas-liquid-solid systems when } \\
\text { temperature and pressure are known, and reaction stoichiometry is } \\
\text { unknown. }\end{array}$ \\
\hline RYIED & $\begin{array}{c}\text { This reactor is useful when reaction stoichiometry and kinetics are unknown, } \\
\text { and the yield distribution data or correlations are available. }\end{array}$ \\
\hline RSTOIC & $\begin{array}{l}\text { This reactor is used to dry raw materials when the reaction kinetics are } \\
\text { unknown, but the reaction stoichiometry and degree are available. }\end{array}$ \\
\hline
\end{tabular}

In the Aspen Plus simulation model of the two-stage ASR pyrolysis and gasification process, the ASR raw streams are first sent to the RSTOIC module, and a FORTRAN statement is used to achieve the drying pretreatment of the ASR at $105^{\circ} \mathrm{C}$. A pyrolysis carrier gas (such as nitrogen, air, etc.) is regulated and controlled by the COMPR module, preheated in the HEATX module, and then mixed with the ASR in the MIXER module. After the ASR is mixed with the carrier gas, it is sent to the DRYER module to separate out the water, and then enters the RYIELD reactor for pyrolysis. Pyrolysis products and gasification agents (such as water vapor, oxygen, etc.) enter the RGIBBS reactor for the gasification reaction.

The ASR pyrolysis and gasification process is complicated, its reaction mechanism is not very clear, the reaction kinetic model is also unknown, and it contains a variety of chemical and phase equilibria. In the RYIELD reactor, the yield distribution can be specified based on the elemental composition data obtained from the industrial analysis of the original ASR. This is why RYIELD is often used as a pyrolysis reactor (Nikoo and Mahinpey 2008; Ahmed et al. 2015; Kaushal and Tyagi 2017; Acevedo et al. 2018; Dhanavath et al. 2018).

The objective of the model was to study the performance of pyrolysis and gasification. The Aspen Plus simulation model of the ASR two-stage pyrolysis and gasification process needs to be established under the following assumptions:

(1) The ASR fragments have the same particle size and are heated uniformly in the reactors without a temperature gradient.

(2) The temperature in the reactors is uniform and constant, and the reactors run stably without fluctuations. 
(3) There is no pressure loss between the reactors, and the internal pressure of the reactor is the same.

(4) Reactions can instantly reach chemical equilibrium.

(5) The $\mathrm{H}, \mathrm{O}, \mathrm{N}$, and $\mathrm{S}$ in the ASR are all transformed into the gas phase, and $\mathrm{C}$ changes with the reaction process.

(6) The gas products are mainly $\mathrm{H}_{2}, \mathrm{CO}, \mathrm{CO}_{2}, \mathrm{CH}_{4}, \mathrm{C}_{2} \mathrm{H}_{4}, \mathrm{C}_{2} \mathrm{H}_{6}, \mathrm{C}_{3} \mathrm{H}_{6}, \mathrm{C}_{3} \mathrm{H}_{8}$, $\mathrm{H}_{2} \mathrm{~S}$, and $\mathrm{NH}_{3}$, and $\mathrm{S}$ and $\mathrm{N}$ are completely converted into $\mathrm{H}_{2} \mathrm{~S}$ and $\mathrm{NH}_{3}$, respectively, without affecting the gasification reaction.

(7) No loss, no pressure drops, and no temperature change occur when the product is transmitted in the pipeline between the modules.

(8) The tar is completely liquefied, and the condensation of the tar in the pipeline between the modules is not considered.

Based on the previous assumptions, the ASR pyrolysis gasification process can be regarded as a constant temperature and pressure reaction process, so the gasification reaction equilibrium model can be established based on the principle of Gibbs free energy minimization (Rupesh et al. 2016). Gibbs free energy minimization is a chemical method based on the RGIBBS reactor function. According to the elemental analysis results of ASR and the related reaction principles of the ASR gasification process, the reaction mechanism function suitable for the ASR gasification process can be written into the GIBBS reactor via the FORTRAN language.

Table 2. Main Reactions Considered in the Aspen Plus Simulation of the ASR Pyrolysis and Gasification Process

\begin{tabular}{|c|c|c|c|}
\hline No. & Reaction Type & Reaction Formula & Reaction Heat \\
\hline R1 & Incomplete oxidation of carbon & $\mathrm{C}+1 / 2 \mathrm{O}_{2} \rightarrow \mathrm{CO}$ & $-111 \mathrm{~kJ} / \mathrm{mol}$ \\
\hline R2 & Complete oxidation of carbon & $\mathrm{C}+\mathrm{O}_{2} \rightarrow \mathrm{CO}_{2}$ & $-394 \mathrm{~kJ} / \mathrm{mol}$ \\
\hline R3 & CO oxidation reaction & $\mathrm{CO}+1 / 2 \mathrm{O}_{2} \rightarrow \mathrm{CO}_{2}$ & $-283 \mathrm{~kJ} / \mathrm{mol}$ \\
\hline R4 & $\mathrm{H}_{2}$ oxidation reaction & $\mathrm{H}_{2}+1 / 2 \mathrm{O}_{2} \rightarrow \mathrm{H}_{2} \mathrm{O}$ & $-242 \mathrm{~kJ} / \mathrm{mol}$ \\
\hline R5 & Incomplete oxidation of hydrocarbons & $\mathrm{CnHm}+\mathrm{n} / 2 \mathrm{O}_{2} \leftrightarrow \mathrm{n} \mathrm{CO}+\mathrm{m}_{2} / 2 \mathrm{H}_{2}$ & Exothermic \\
\hline R6 & Water-gas reaction & $\mathrm{C}+\mathrm{H}_{2} \mathrm{O} \leftrightarrow \mathrm{CO}+\mathrm{H}_{2}$ & $+131 \mathrm{~kJ} / \mathrm{mol}$ \\
\hline R7 & Water-gas conversion reaction & $\mathrm{CO}+\mathrm{H}_{2} \mathrm{O} \leftrightarrow \mathrm{CO}_{2}+\mathrm{H}_{2}$ & $-41.2 \mathrm{~kJ} / \mathrm{mol}$ \\
\hline R8 & Hydrogenation gasification reaction & $\mathrm{C}+2 \mathrm{H}_{2} \rightarrow \mathrm{CH}_{4}$ & $-74.8 \mathrm{~kJ} / \mathrm{mol}$ \\
\hline R9 & Methanation reaction-1 & $2 \mathrm{CO}+2 \mathrm{H}_{2} \rightarrow \mathrm{CH}_{4}+\mathrm{CO}_{2}$ & $-247 \mathrm{~kJ} / \mathrm{mol}$ \\
\hline R10 & Methanation reaction-2 & $\mathrm{CO}+3 \mathrm{H}_{2} \rightarrow \mathrm{CH}_{4}+\mathrm{H}_{2} \mathrm{O}$ & $-206 \mathrm{~kJ} / \mathrm{mol}$ \\
\hline R11 & Methanation reaction-3 & $\mathrm{CO}+4 \mathrm{H}_{2} \rightarrow \mathrm{CH}_{4}+\mathrm{H}_{2} \mathrm{O}$ & $-165 \mathrm{~kJ} / \mathrm{mol}$ \\
\hline R12 & Boundouard reaction & $\mathrm{C}+\mathrm{CO}_{\leftrightarrow} \leftrightarrow 2 \mathrm{CO}$ & $+172 \mathrm{~kJ} / \mathrm{mol}$ \\
\hline R13 & Steam reforming reaction & $\mathrm{CnHm}+\mathrm{nH} 2 \mathrm{O} \leftrightarrow \mathrm{nCO}+\left(\mathrm{n}+\mathrm{m}_{2} / 2\right) \mathrm{H}_{2}$ & Endothermic \\
\hline R14 & Methane reforming reaction-1 & $\mathrm{CH} 4+\mathrm{H}_{2} \mathrm{O} \rightarrow \mathrm{CO}+3 \mathrm{H}_{2}$ & $+206 \mathrm{~kJ} / \mathrm{mol}$ \\
\hline R15 & Methane reforming reaction-2 & $\mathrm{CH} 4+1 / 2 \mathrm{O}_{2} \rightarrow \mathrm{CO}+2 \mathrm{H}_{2}$ & $-36 \mathrm{~kJ} / \mathrm{mol}$ \\
\hline R16 & Carbon dioxide reforming reaction & $\mathrm{CnHm}+\mathrm{nCO} 2 \leftrightarrow 2 \mathrm{nCO}+\mathrm{m}_{2} / 2 \mathrm{H}_{2}$ & Endothermic \\
\hline R17 & Dehydrogenation reaction & $\mathrm{Tar} \rightarrow \mathrm{x} \mathrm{CnHm}+\mathrm{y} \mathrm{H} \mathrm{H}_{2}$ & Endothermic \\
\hline R18 & Carbon evolution reaction & $\mathrm{CnHm} \rightarrow \mathrm{nC}+\mathrm{m} / 2 \mathrm{H}_{2}$ & Endothermic \\
\hline
\end{tabular}

\section{Calculation Method of the Quantitative Parameters}

The purpose of this work was to obtain the ASR pyrolysis gas gasification process parameters that maximizes the syngas and hydrogen yields. For this purpose, the controlled variable method was used for a simulation analysis of the established ASR two-stage pyrolysis gasification Aspen plus simulation model under the premise of satisfying the mass balance, energy balance, and chemical equilibrium. The main oxidation reaction, 
gasification reaction, Boundouard reaction, methanation reaction, methane reforming reaction, and cracking reaction of tar and hydrocarbon in the ASR pyrolysis and gasification process, are shown in Table 2. It can be seen from these main reactions that the main process parameters that affect the gas product distribution of the ASR pyrolysis and gasification process include the pyrolysis temperature, gasification temperature, mass ratio of water vapor to ASR, equivalent ratio, etc.

To quantitatively analyze the effect of various process parameters in the ASR pyrolysis and gasification process, the following process parameters and evaluation indicators are introduced.

The $S / W$ refers to the mass ratio of steam to ASR during the pyrolysis and gasification process. The calculation formula is as follows,

$$
\frac{S}{W}=\frac{Q_{s}}{Q_{w}}
$$

where $Q$ s refers to the mass flow rate of water vapor $(\mathrm{kg} / \mathrm{h})$, and $Q \mathrm{w}$ refers to the feed rate of the ASR sample $(\mathrm{kg} / \mathrm{h})$.

The ER (equivalent ratio) refers to the ratio of the actual amount of oxygen consumed by the unit mass ASR pyrolysis and gasification process to the theoretical amount of oxygen consumed by ASR complete combustion. The calculation formula is as follows,

$$
E R=\frac{Q_{o} \cdot O_{c}}{21 Q_{W} \cdot V_{a}}
$$

where $Q_{\mathrm{o}}$ refers to the volumetric flow rate of compressed air $\left(\mathrm{Nm}^{3} / \mathrm{h}\right), Q_{\mathrm{c}}$ refers to the

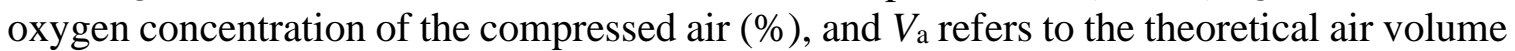
required for the complete combustion of $\mathrm{ASR}\left(\mathrm{Nm}^{3} / \mathrm{kg}\right)$.

The LHV (lower heating value) refers to the chemical energy contained in the unit volume syngas obtained via ASR pyrolysis gasification under standard temperature and pressure. The calculation formula is as follows,

$$
\begin{aligned}
\mathrm{LHV}= & 12.64 \varphi(\mathrm{CO})+10.8 \varphi\left(\mathrm{H}_{2}\right)+35.88 \varphi\left(\mathrm{CH}_{4}\right)+59.44 \varphi\left(\mathrm{C}_{2} \mathrm{H}_{4}\right) \\
& +\varphi\left(\mathrm{C}_{2} \mathrm{H}_{6}\right) \times 64.35+87.61 \varphi\left(\mathrm{C}_{3} \mathrm{H}_{6}\right)+93.18 \varphi\left(\mathrm{C}_{3} \mathrm{H}_{8}\right)
\end{aligned}
$$

where $\varphi(\mathrm{CO}), \varphi\left(\mathrm{H}_{2}\right), \varphi\left(\mathrm{CH}_{4}\right), \varphi\left(\mathrm{C}_{2} \mathrm{H}_{4}\right), \varphi\left(\mathrm{C}_{2} \mathrm{H}_{6}\right), \varphi\left(\mathrm{C}_{3} \mathrm{H}_{6}\right)$, and $\varphi\left(\mathrm{C}_{3} \mathrm{H}_{8}\right)$ refer to the volume fractions of $\mathrm{CO}, \mathrm{H}_{2}, \mathrm{CH}_{4}, \mathrm{C}_{2} \mathrm{H}_{4}, \mathrm{C}_{2} \mathrm{H}_{6}, \mathrm{C}_{3} \mathrm{H}_{6}$, and $\mathrm{C}_{3} \mathrm{H}_{8}$ in the syngas, respectively.

$Y_{\mathrm{g}}$ refers to the volume of syngas obtained by the unit mass ASR pyrolysis and gasification under standard temperature and pressure $\left(\mathrm{Nm}^{3} / \mathrm{kg}\right)$. The calculation formula is as follows,

$$
Y_{g}=Q_{g} / Q_{w}
$$

where $Q_{\mathrm{g}}$ refers to the volumetric flow rate of hydrogen-rich gas obtained via ASR pyrolysis and gasification $\left(\mathrm{Nm}^{3} / \mathrm{h}\right)$.

The $\mathrm{CVR}_{\mathrm{C}}$ (carbon conversion rate) refers to the ratio of the carbon content of syngas obtained from the unit mass ASR pyrolysis and gasification to the total carbon content of the ASR sample. The calculation formula is as follows,

$$
\mathrm{CVR}_{\mathrm{C}}=\frac{12 \mathrm{Y}_{\mathrm{g}} \times\left(\varphi(\mathrm{CO})+\varphi\left(\mathrm{CO}_{2}\right)+\varphi\left(\mathrm{CH}_{4}\right)+\varphi\left(\mathrm{C}_{2} \mathrm{H}_{4}\right)+\varphi\left(\mathrm{C}_{2} \mathrm{H}_{6}\right)+\varphi\left(\mathrm{C}_{3} \mathrm{H}_{6}\right)+\varphi\left(\mathrm{C}_{3} \mathrm{H}_{8}\right)\right.}{22.4 \times \mathrm{C}_{A S R}} \times 100 \%
$$


where $\mathrm{C}_{\mathrm{ASR}}$ refers to the percentage value of the carbon content in the dry ASR sample $(\%)$, and $\varphi\left(\mathrm{CO}_{2}\right)$ refers to the volume fraction of $\mathrm{CO}_{2}$ in the syngas obtained by ASR pyrolysis and gasification $(\%)$.

The parameter $\eta$ (Cold-gas efficiency) refers to the ratio of the total heat of the syngas of ASR pyrolysis and gasification to the low calorific value of ASR. The calculation formula is as follows,

$$
\eta=\frac{\mathrm{LHV} \times \mathrm{Y}_{g}}{\mathrm{Q}_{A S R}} \times 100 \%
$$

where QASR refers to the low calorific value of ASR (MJ/kg).

The parameter $Y_{\mathrm{H} 2}$ (yield of $\mathrm{H}_{2}$ ) refers to the volume of hydrogen obtained by the unit mass ASR pyrolysis and gasification under standard temperature and pressure $\left(\mathrm{Nm}^{3} / \mathrm{kg}\right)$,

$$
Y_{H 2}=\frac{Y_{g} \cdot \varphi\left(\mathrm{H}_{2}\right)}{100}
$$

where $\varphi\left(\mathrm{H}_{2}\right)$ refers to the volume fraction of $\mathrm{H}_{2}$ in the syngas obtained by ASR pyrolysis and gasification $(\%)$.

\section{Experimental Conditions of the Simulation Analysis}

The ASR specimens studied in this work were obtained from Zhangjiagang Huaren Resources Recycling Co., Ltd. (Zhangjiagang City, China), a domestic automobile dismantling enterprise. Reusable components with market value and particularly valuable material fractions, such as batteries, air bags, tires, and catalytic converters are usually removed from ELVs. The remaining parts and the hulks are reduced to small pieces. Most of the metal fraction is sorted using magnetic separation and eddy current separation, and the remaining fraction is called ASR. The initial ASR specimens were continuously obtained over one week from a crushing and sorting production line for ELVs. Visible bulks of metal to the human eye were sought from the ASR initial specimens. Industrial analysis and element analysis experiments were performed on the ASR, with the analysis results shown in Table 3.

\begin{tabular}{|c|c|c|c|c|c|c|c|c|}
\hline \multicolumn{5}{|c|}{ Industrial Analysis (wt\%) } & \multicolumn{4}{|c|}{ Low Heating Value (LHV) (MJ/kg) } \\
\hline Moisture & Volatile & Ash & \multirow{2}{*}{\multicolumn{2}{|c|}{$\frac{\text { Fixed Carbon }}{10306}$}} & \multirow{2}{*}{\multicolumn{4}{|c|}{17.435}} \\
\hline 1.114 & 63.982 & 24.598 & & & & & & \\
\hline \multicolumn{9}{|c|}{ Metal Elemental Analysis (wt\%) } \\
\hline $\mathrm{Fe}$ & $\mathrm{Cu}$ & $\mathrm{Al}$ & $\mathrm{Mg}$ & $\mathrm{Cr}$ & $\mathrm{Mn}$ & $\mathrm{Ni}$ & $\mathrm{Pb}$ & $\mathrm{Zn}$ \\
\hline 8.275 & 2.15 & 0.619 & 0.257 & 0.046 & 0.059 & 0.013 & 0.336 & 0.855 \\
\hline \multicolumn{9}{|c|}{ Non-Metal Elemental Analysis (wt\%) } \\
\hline C & $\mathrm{H}$ & $\mathrm{O}$ & $\mathrm{Cl}$ & $\mathrm{N}$ & \multicolumn{4}{|c|}{ S } \\
\hline 49.22 & 3.46 & 25.79 & 6.08 & 0.97 & \multicolumn{4}{|c|}{0.29} \\
\hline \multicolumn{9}{|c|}{ Material composition (wt\%) } \\
\hline Items & Metal & Plastic & Textile & Rubber & \multicolumn{2}{|c|}{ Foam } & \multicolumn{2}{|c|}{ others } \\
\hline $\mathrm{Wt} \%$ & 3.0 & 39.7 & 31.4 & 3.3 & \multicolumn{2}{|c|}{2.2} & \multicolumn{2}{|c|}{21.7} \\
\hline
\end{tabular}

Table 3. Analysis Results of the Physical and Chemical Properties of ASR

In the Aspen Plus model of ASR pyrolysis and gasification, the initial process parameters and operating conditions are set as follows: 
(1) The ASR feed stream inlet temperature is $20^{\circ} \mathrm{C}$, and the initial feed rate of the ASR is $10 \mathrm{~kg} / \mathrm{h}$.

(2) The air is introduced at an ambient temperature of $20^{\circ} \mathrm{C}$ and under normal pressure, and the mass flow rate of the introduced air is $10 \mathrm{~kg} / \mathrm{h}$.

(3) The outlet temperature of the HEATX module and DRYER module was set to $105^{\circ} \mathrm{C}$.

(4) The operating pressure of each reactor was set to $1 \mathrm{~atm}$.

(5) The carbon loss rate of the RYIELD pyrolyzer and GIBBS gasifier was set to $2 \%$.

(6) The heat loss of the simulation model was calculated as $3 \%$ of the input ASR calorific value.

The pyrolysis and gasification reaction process shown in Table 2 includes a series of endothermic reactions. In the Aspen Plus simulation analysis process, the RYIELD pyrolyzer temperature was set to $500{ }^{\circ} \mathrm{C}, 600{ }^{\circ} \mathrm{C}, 700{ }^{\circ} \mathrm{C}$, and $800{ }^{\circ} \mathrm{C}$, and the GIBBS gasifier temperature was set to $800^{\circ} \mathrm{C}, 900^{\circ} \mathrm{C}, 1000^{\circ} \mathrm{C}, 1100{ }^{\circ} \mathrm{C}$, and $1200^{\circ} \mathrm{C}$.

\section{Experimental Method of the Laboratory Experiments}

Based on the research work of ASR pyrolysis kinetics (Yang and Chen 2020a), a characteristic analysis of ASR pyrolysis products (Yang and Chen 2020b) and a simulation analysis of the ASR pyrolysis gasification process based on Aspen Plus, two-stage ASR pyrolysis and gasification experimental equipment was established as shown in Fig. 2. The experimental samples were the same as previously mentioned, and the basic characteristics are shown in Table 3. The original ASR is broken into pieces less than $10 \mathrm{~mm}$ in size. The initial mass of all the samples was controlled at $50 \pm 0.2 \mathrm{~g}$ using a Mettler Toledo analytical balance (Changzhou, China).

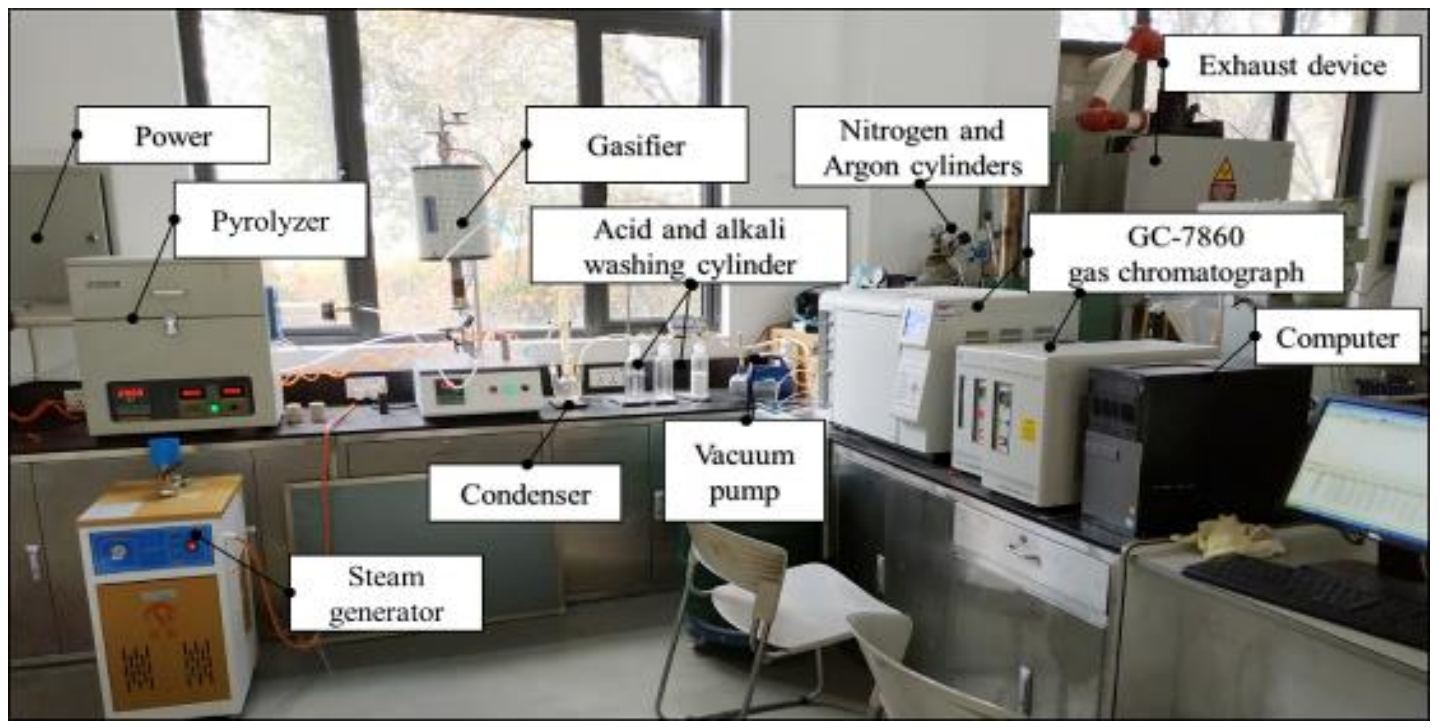

Fig. 2. Two-stage ASR pyrolysis and gasification experimental equipment

According to the analysis of the process parameters, such as pyrolysis temperature, gasification temperature, ER, and $S / W$, experiments were conducted to evaluate the accuracy and reliability of the simulation analysis results based on the Aspen Plus model. In the pyrolysis experiment, the long crucible with the ASR sample was put into the quartz 
tube of the pyrolysis furnace and pushed to the central thermal stability zone. First, a vacuum pump was used to exhaust the internal air of the equipment; the temperature of the pyrolysis furnace and the gasifier was heated to $105^{\circ} \mathrm{C}$ at a heating rate of $10^{\circ} \mathrm{C} / \mathrm{min}$. After $30 \mathrm{~min}$, the temperature of the pyrolysis furnace was maintained at $105^{\circ} \mathrm{C}$, while the temperature of the gasifier was increased to $1000{ }^{\circ} \mathrm{C}$ at a heating rate of $10{ }^{\circ} \mathrm{C} / \mathrm{min}$. Then, the gas outlet was closed and the vacuum pump was turned off. The pyrolysis furnace temperature was increased to $600{ }^{\circ} \mathrm{C}$ at the heating rate of $10^{\circ} \mathrm{C} / \mathrm{min}$. After the pyrolysis furnace reached $60^{\circ} \mathrm{C}$, the steam was injected according to an $\mathrm{S} / \mathrm{W}$ ratio of 0.75 , and then the gas outlet was opened for a period of time, and multiple sampling analyses of the gas products were conducted. The production of $\mathrm{H}_{2}, \mathrm{CO}, \mathrm{CO}_{2}, \mathrm{CH}_{4}, \mathrm{C}_{2} \mathrm{H}_{4}, \mathrm{C}_{3} \mathrm{H}_{6}, \mathrm{C}_{2} \mathrm{H}_{6}$, and $\mathrm{C}_{3} \mathrm{H}_{8}$ in gas products was characterized with a GC-7860 gas chromatograph (Shanghai Appropriate Friends Electronic Technology Co., Ltd., Shanghai, China).

\section{RESULTS AND DISCUSSION}

\section{Simulation Analysis of The Effect of Temperature and ER on the ASR Pyrolysis and Gasification Process}

The byproduct characteristics of the ASR pyrolysis gasification process were simulated during the change in the ER value in the range of 0 to 0.5 in the absence of steam. The volume fractions of $\mathrm{H}_{2}, \mathrm{CO}$, and $\mathrm{CO}_{2}$ in the gas product during the ASR pyrolysis and gasification process corresponding to different pyrolysis temperatures and ER are reflected in Figs. 3, 4, and 5, respectively.

From the hydrogen yield curves in Fig. 3, the following reaction patterns can be summarized. With an increasing pyrolysis temperature, the production of $\mathrm{H}_{2}$ gradually increased. The maximum $\mathrm{H}_{2}$ production was approximately $600{ }^{\circ} \mathrm{C}$, and if the pyrolysis temperature continued to increase, the hydrogen production decreased. The main reason for this phenomenon was that the organic components of ASR were almost completely pyrolyzed at $600{ }^{\circ} \mathrm{C}$, and then part of the produced $\mathrm{H}_{2}$ was consumed due to participation in the hydrogenation reaction, methanization reaction, or secondary pyrolysis reaction of macromolecule intermediate reactants at higher temperatures. In the reactor of the Aspen Plus simulation model, the chemical reaction will proceed instantly, as long as the relevant conditions are reached. In addition, in the temperature range of 700 to $800{ }^{\circ} \mathrm{C}$, more carbon is involved in the chemical reactions, and the increase in $\mathrm{CO}$ and $\mathrm{CO}_{2}$ contents in the gas products leads to a decrease in the proportion of $\mathrm{H}_{2}$.

When the pyrolysis temperature and ER were kept at a specified value, the production of $\mathrm{H}_{2}$ gradually increased with an increasing gasification temperature in the range of 800 to $1000{ }^{\circ} \mathrm{C}$. The gasification temperature increased per $100{ }^{\circ} \mathrm{C}$, an approximate $7 \%$ increase in $\mathrm{H}_{2}$ production. This is mainly due to the rapid occurrence of chemical reactions, such as condensation reactions of aromatic rings, cracking reactions of saturated hydrocarbons, methane reforming reactions, and dehydrogenation reactions. When the gasification temperature was higher than $1000{ }^{\circ} \mathrm{C}$, the production of $\mathrm{H}_{2}$ decreased slowly with an increasing gasification temperature. This result was mainly due to the secondary reaction of the polymerization and isomerization of some products under ultrahigh temperature, which consumed a portion of hydrogen. 

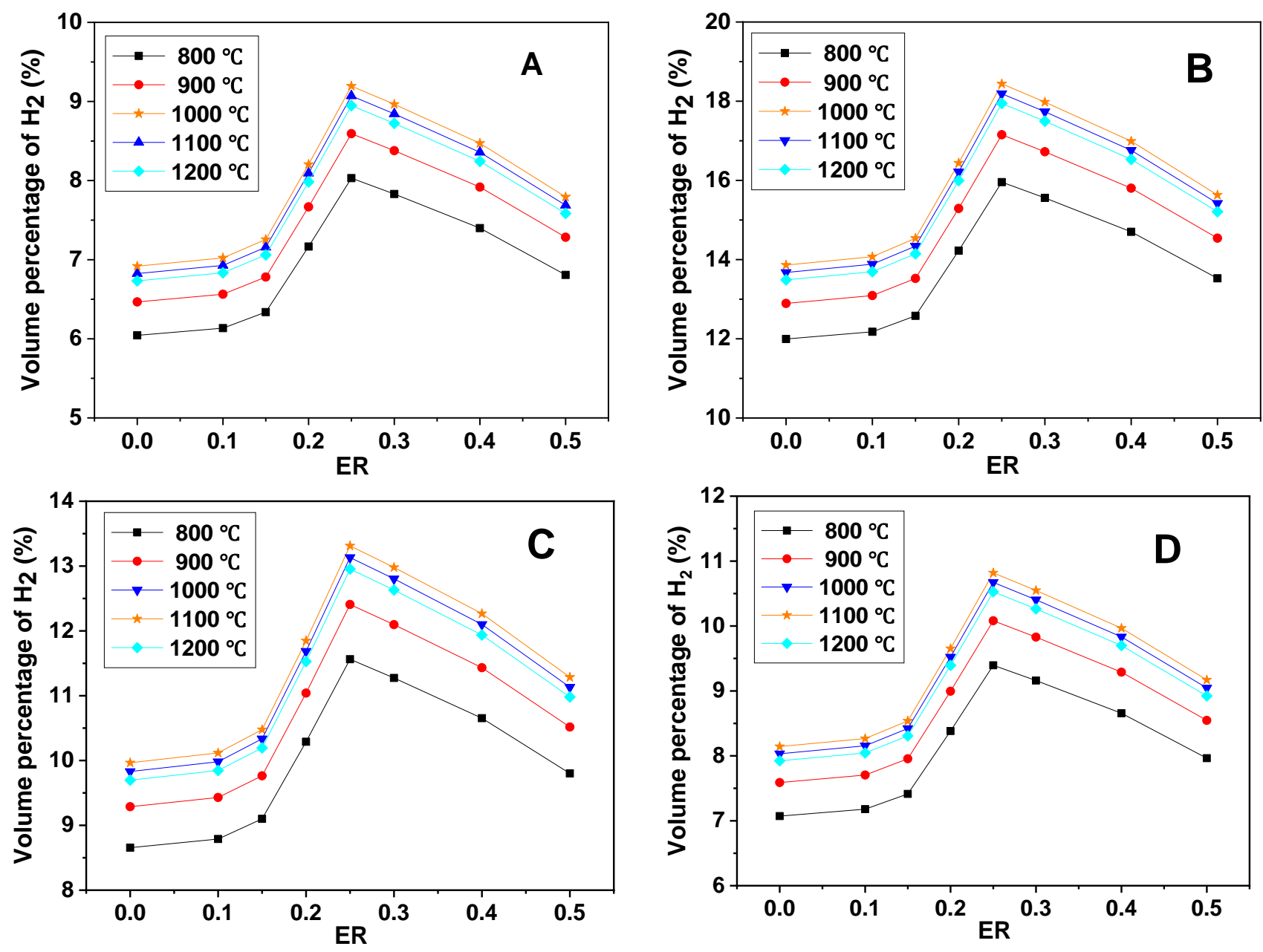

Fig. 3. $\mathrm{H}_{2}$ production at different gasification temperatures and $\mathrm{ER}$ when the pyrolysis temperatures were different: A) $500^{\circ} \mathrm{C}$, B) $600^{\circ} \mathrm{C}$, C) $700^{\circ} \mathrm{C}$, and D) $800^{\circ} \mathrm{C}$

When the pyrolysis temperature and gasification temperature were kept at a specified value and the ER value varied in the range of 0 to 0.25 , the $\mathrm{H}_{2}$ production increased with an increasing ER value. When $0<\mathrm{ER}<0.15$, the growth rate of $\mathrm{H}_{2}$ production was relatively slow, whereas when $0.15<\mathrm{ER}<0.25$, the growth rate of $\mathrm{H}_{2}$ production was relatively fast. This is mainly because more $\mathrm{CO}$ was generated by the incomplete oxidation reaction of carbon as the oxygen concentration increased, which formed a certain reducing atmosphere and promoted more intermediate reactants to participate in the gasification reaction. When the ER value was above $0.25, \mathrm{H}_{2}$ production began to decrease. This is mainly because the $\mathrm{CO}_{2}$ content increased dramatically via the complete oxidation reaction of carbon as the oxygen concentration increased, which consumed a substantial amount of heat and inhibited the gasification reaction.

The CO production of ASR pyrolysis and gasification is reflected in Fig. 4. Compared with the $\mathrm{H}_{2}$ production shown in Fig. 3, the overall trends of $\mathrm{H}_{2}$ and $\mathrm{CO}$ production with pyrolysis temperature and ER were roughly the same when the gasification temperature was fixed at a certain value. When the pyrolysis temperature and ER were kept at a specified value, the higher the gasification temperature, the more $\mathrm{CO}$ produced, with a 1 to $2 \%$ increase per $100{ }^{\circ} \mathrm{C}$. 

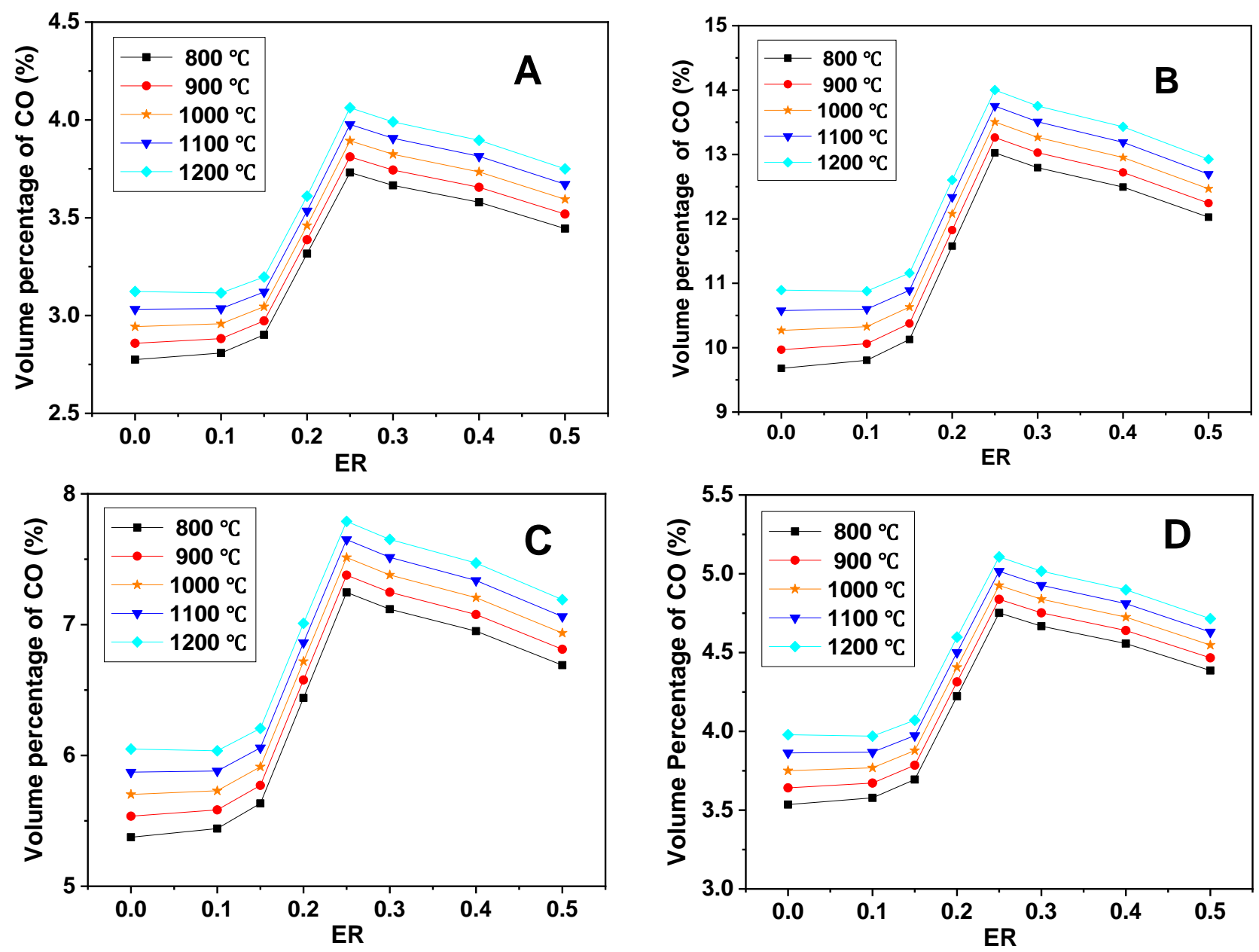

Fig. 4. CO production at different gasification temperatures and $E R$ when the pyrolysis temperatures were different: A) $500^{\circ} \mathrm{C}$, B) $600^{\circ} \mathrm{C}$, C) $700^{\circ} \mathrm{C}$, and D) $800^{\circ} \mathrm{C}$

The $\mathrm{CO}_{2}$ production at different gasification temperatures and ER when the pyrolysis temperatures were 500, 600, 700, and $800{ }^{\circ} \mathrm{C}$ are shown in Fig. 5. From Fig. 5, the following reaction patterns can be summarized. When the pyrolysis temperature and ER were fixed, the production of $\mathrm{CO}_{2}$ gradually decreased with an increasing gasification temperature in the range of 800 to $1000{ }^{\circ} \mathrm{C}$. The gasification temperature increased per 100 ${ }^{\circ} \mathrm{C}$, an approximately $7 \%$ increase in $\mathrm{CO}_{2}$ production. After the gasification temperature was higher than $1100{ }^{\circ} \mathrm{C}$, the $\mathrm{CO}_{2}$ production decreased faster, with a $37.6 \%$ increase per $100{ }^{\circ} \mathrm{C}$. This result was mainly because $\mathrm{CO}_{2}$ was greatly consumed due to participation in the Boundouard reaction and carbon dioxide reforming reaction. When the pyrolysis temperature and gasification temperature were kept constant and the ER value varied in the range of 0 to 0.5 , the $\mathrm{CO}_{2}$ production increased with an increasing ER value. When $0<\mathrm{ER}$ $<0.15$, the growth rate of $\mathrm{CO}_{2}$ production was relatively slow, especially when the pyrolysis temperature was set below $600{ }^{\circ} \mathrm{C}$. Carbon dioxide is mainly produced by a decarboxylation reaction rather than a complete oxidation reaction of carbon. The decarboxylation reaction was generally complete below $700{ }^{\circ} \mathrm{C}$. When $0.15<\mathrm{ER}<0.25$, the growth rate of $\mathrm{CO}_{2}$ production continued to accelerate. When ER $>0.25$, the growth rate of $\mathrm{CO}_{2}$ production increased sharply because most of the carbon in the ASR was conducted during the complete oxidation reaction, generating a large amount of $\mathrm{CO}_{2}$. 
According to Eq. 8, the main factors affecting the LHV value are the content of CO, $\mathrm{H}_{2}$, and other small-molecule combustible gases. Comparing the experimental data, it was found that the production of $\mathrm{CH}_{4}, \mathrm{C}_{2} \mathrm{H}_{4}, \mathrm{C}_{3} \mathrm{H}_{6}, \mathrm{C}_{2} \mathrm{H}_{6}$, and $\mathrm{C}_{3} \mathrm{H}_{8}$ accounted for a low proportion of gas products during the ASR pyrolysis and gasification process. The overall production trends of $\mathrm{CH}_{4}, \mathrm{C}_{2} \mathrm{H}_{4}, \mathrm{C}_{3} \mathrm{H}_{6}, \mathrm{C}_{2} \mathrm{H}_{6}$, and $\mathrm{C}_{3} \mathrm{H}_{8}$ with the pyrolysis temperature and ER were roughly the same at four pyrolysis temperatures, i.e., $500{ }^{\circ} \mathrm{C}, 600{ }^{\circ} \mathrm{C}, 700{ }^{\circ} \mathrm{C}$, and $800{ }^{\circ} \mathrm{C}$. Thus, the authors only analyzed the simulation data obtained when the pyrolysis temperature was set to $500{ }^{\circ} \mathrm{C}$, as shown in Fig. 5 .
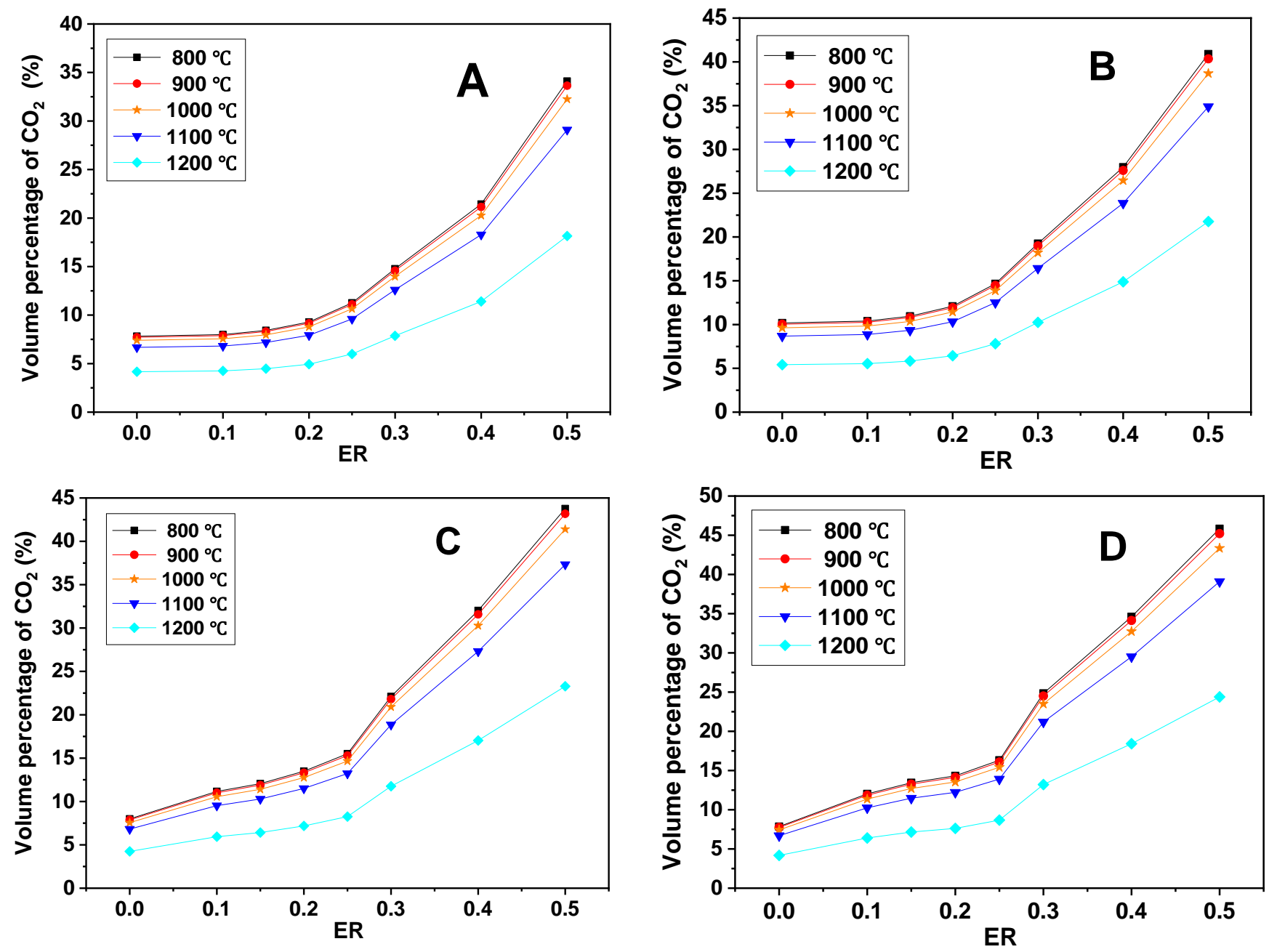

Fig. 5. $\mathrm{CO}_{2}$ production at different gasification temperatures and $\mathrm{ER}$ when the pyrolysis temperatures were different: A) $500^{\circ} \mathrm{C}$, B) $600^{\circ} \mathrm{C}$, C) $700^{\circ} \mathrm{C}$, and D) $800^{\circ} \mathrm{C}$

The methane produced by ASR pyrolysis and gasification mainly comes from the reduction reaction of methoxy groups in organic molecules, the cross-linking reaction of macromolecules at a high temperature, and the thermal cracking reaction of saturated alkanes $\left(>\mathrm{C}_{2}\right)$. The curves in Fig. 6A show that the oxygen content had little effect on $\mathrm{CH}_{4}$. The volume fraction of $\mathrm{CH}_{4}$ only increased slightly when $\mathrm{ER}<0.1$, and when $\mathrm{ER}>0.1$, the volume fraction of $\mathrm{CH}_{4}$ was hardly affected by the oxygen content. The change in the gasification temperature has an obvious influence on $\mathrm{CH}_{4}$. The volume fraction of $\mathrm{CH}_{4}$ increased with an increasing gasification temperature in the range of 800 to $1000^{\circ} \mathrm{C}$. After 
the gasification temperature was higher than $1000{ }^{\circ} \mathrm{C}$, the volume fraction of $\mathrm{CH}_{4}$ decreased rapidly with an increasing gasification temperature. Secondary cracking reactions of macromolecules, such as aromatics in tar, were more likely to occur, and thus, more hydrogen and oxygen were precipitated, resulting in a decrease in $\mathrm{CH}_{4}$ production. The methanation reaction and the methane reforming reaction coexist in the ASR pyrolysis and gasification process. In the RYIELD pyrolyzer and GIBBS gasifier, various chemical reactions proceed instantly as long as the relevant conditions are met. Therefore, $\mathrm{CH}_{4}$ acted more as an intermediate reactant in the Aspen plus simulation model.
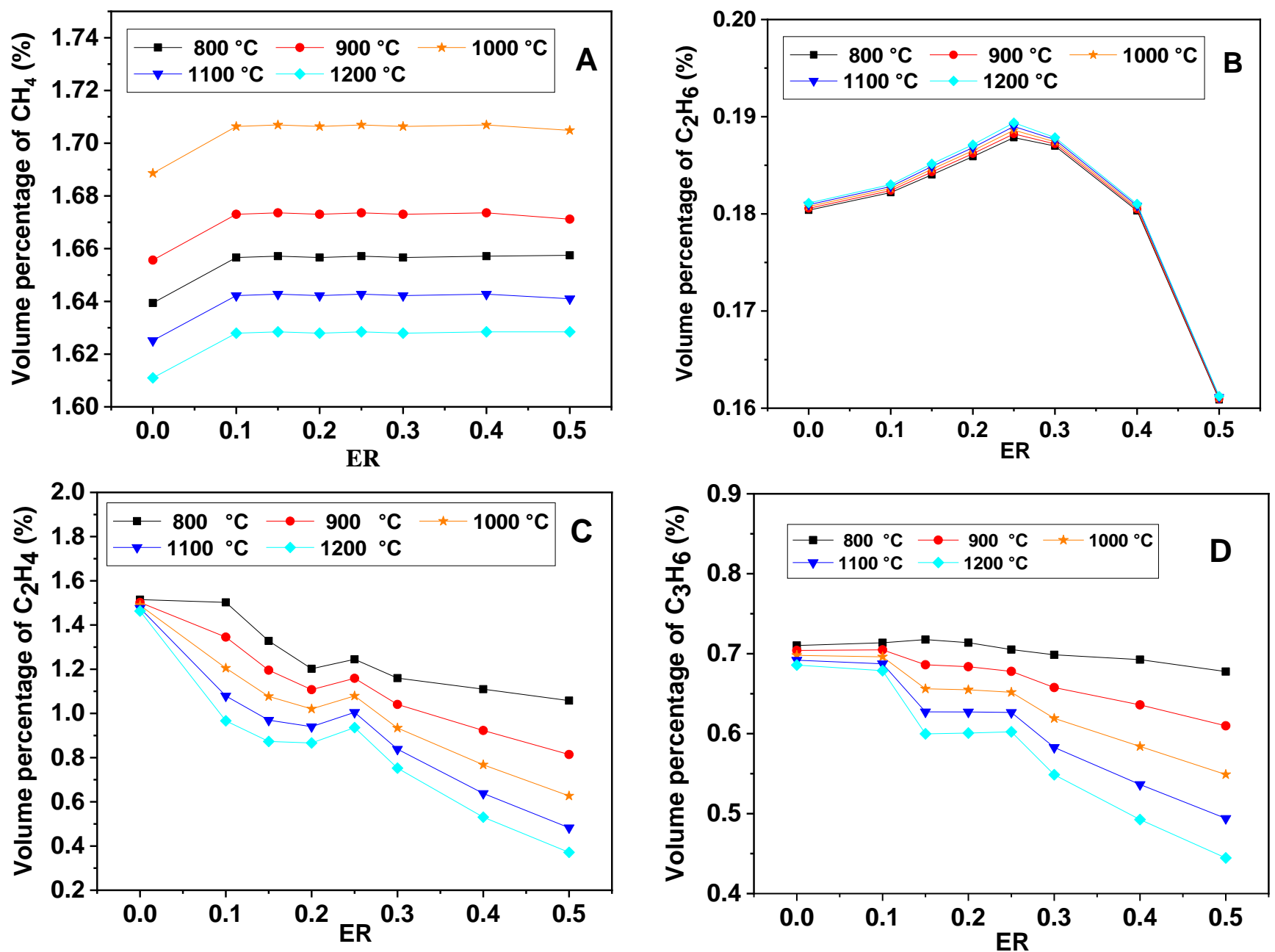

Fig. 6. The production of $\mathrm{CH}_{4}, \mathrm{C}_{2} \mathrm{H}_{4}, \mathrm{C}_{3} \mathrm{H}_{6}$, and $\mathrm{C}_{2} \mathrm{H}_{6}$ at different gasification temperatures and ER when the pyrolysis temperature was $500{ }^{\circ} \mathrm{C}$ : A) $\left.\left.\mathrm{CH}_{4}, \mathrm{~B}\right) \mathrm{C}_{2} \mathrm{H}_{6}, \mathrm{C}\right) \mathrm{C}_{2} \mathrm{H}_{4}$, and D) $\mathrm{C}_{3} \mathrm{H}_{6}$

Considering that the $\mathrm{C}_{2} \mathrm{H}_{6}$ and $\mathrm{C}_{3} \mathrm{H}_{8}$ contents were particularly low and their production trends were similar, only the $\mathrm{C}_{2} \mathrm{H}_{6}$ production curves are shown in Fig. $6 \mathrm{~B}$. The gasification temperature had little effect on the production of these two alkanes. When $0<$ ER $<0.25$, the volume fractions of the two gases slowly increased; after ER $>0.25$, the volume fractions of these two alkanes immediately decreased or even disappeared. These two alkanes are prone to oxidation reactions under high temperature and oxygen-rich conditions, generating $\mathrm{CO}_{2}$ and $\mathrm{H}_{2} \mathrm{O}$. 
The production changes of $\mathrm{C}_{2} \mathrm{H}_{4}$ and $\mathrm{C}_{3} \mathrm{H}_{6}$ are roughly the same in the ASR pyrolysis and gasification process, as shown in Figs. 5C and 5D. As the gasification temperature increased, the volume fraction of these two olefin gases decreased. With an increasing ER value, their volume fractions generally showed a downward trend, falling faster and faster because these two olefin gases are easily oxidized at high temperatures. However, there was a small fluctuation in the range of $0.15<\mathrm{ER}<0.25$, mainly because a large amount of $\mathrm{CO}$ and $\mathrm{H}_{2}$ were produced, and then a certain reducing atmosphere was formed, which led to a small increase in the olefin gas.

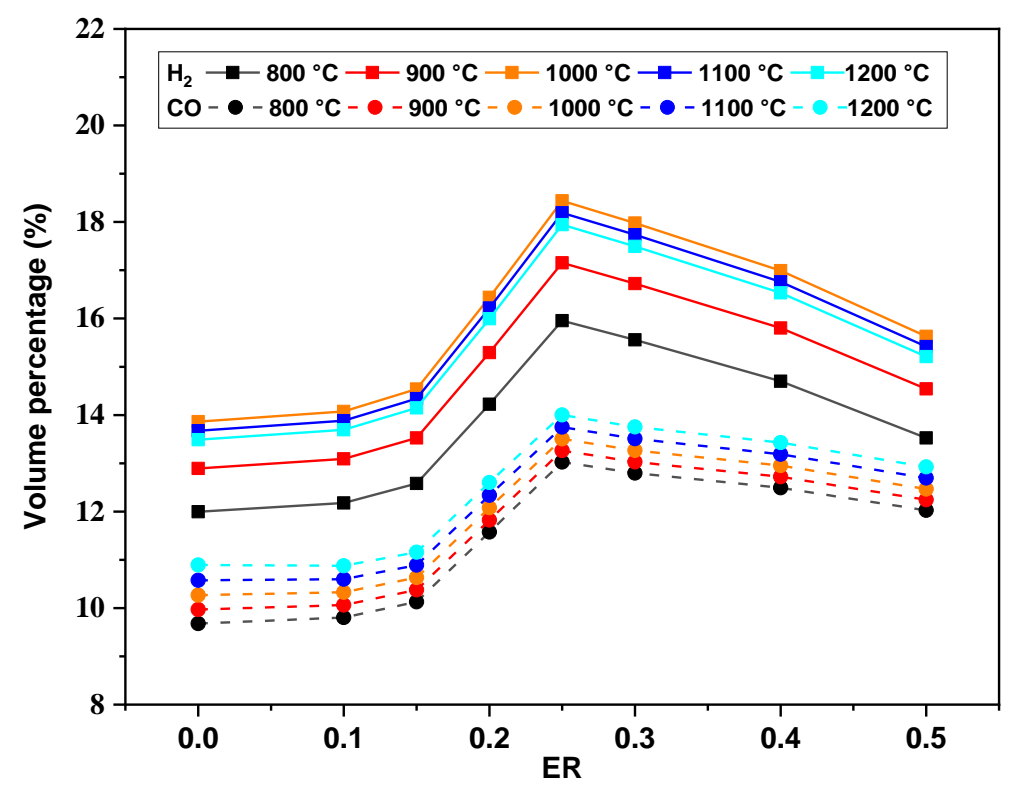

Fig. 7. $\mathrm{H}_{2}$ and $\mathrm{CO}$ yields under different $\mathrm{ER}$ and gasification temperatures when the pyrolysis temperature was $600^{\circ} \mathrm{C}$

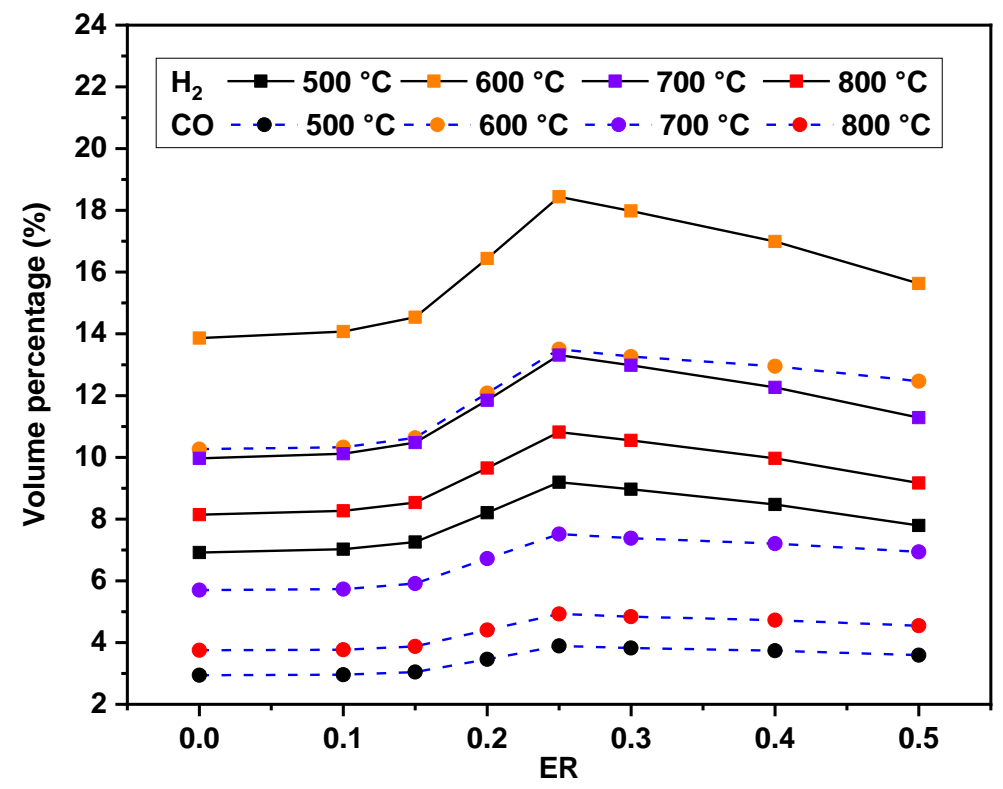

Fig. 8. $\mathrm{H}_{2}$ and $\mathrm{CO}$ yields under different $\mathrm{ER}$ and pyrolysis temperatures, whereas the gasification temperature was $1000^{\circ} \mathrm{C}$ 
Based on the above analysis in Figs. 3 through 6, it can be inferred that the optimal ER value was 0.25 . Because $\mathrm{CO}_{2}$ is relatively small under this condition, the production of combustible gases, such as $\mathrm{CO}$ and $\mathrm{H}_{2}$, is relatively large. The volume fraction ratio of $\mathrm{H}_{2}$ to $\mathrm{CO}$ was controlled within the range of 1.0 to 2.0 , which was more conducive to using the pyrolysis gas product as the raw gas for the hydrogen production process. A larger ratio resulted in a better hydrogen production effect. Based on the simulation results of the ASR pyrolysis and gasification process in the Aspen Plus model, comparative analysis diagrams of $\mathrm{CO}$ and $\mathrm{H}_{2}$ production under different reaction conditions were established, as shown in Figs. 7 and 8. Figure 7 reflects the $\mathrm{CO}$ and $\mathrm{H}_{2}$ yields under different $\mathrm{ER}$ and gasification temperatures when the pyrolysis temperature was $600{ }^{\circ} \mathrm{C}$. Figure 8 reflects the $\mathrm{CO}$ and $\mathrm{H}_{2}$ yields under different ER and pyrolysis temperatures, whereas the gasification temperature was $1000^{\circ} \mathrm{C}$. After a comprehensive analysis of Figs. 7 and 8, it was determined that when the pyrolysis temperature was $600{ }^{\circ} \mathrm{C}$, the gasification temperature was $1000{ }^{\circ} \mathrm{C}$ and $\mathrm{ER}=$ 0.25 , the volume fraction of $\mathrm{H}_{2}$ obtained from the ASR pyrolysis and gasification was the largest, and $\varphi\left(\mathrm{H}_{2}\right) / \varphi(\mathrm{CO})=1.365$. Therefore, it can be concluded that the combination of these experimental conditions was optimal. Further research on the design and optimization of process parameters, such as steam and the catalyst, will also be conducted based on this combination of experimental conditions.

\section{Simulation Analysis of The Effect of Steam on the ASR Pyrolysis Gasification Process}

When steam is used as the gasification agent for the ASR pyrolysis and gasification process, steam and the primary pyrolysis products (such as tar, biochar, etc.) will undergo a thermochemical conversion reaction. The specific reaction types are shown in Table 2 . Through controlling this series of reactions, the goal of reducing tar and biochar production and increasing gas production, especially the production of $\mathrm{H}_{2}, \mathrm{CO}, \mathrm{CO}_{2}, \mathrm{CH}_{4}$, and other small molecular gases, can be achieved.

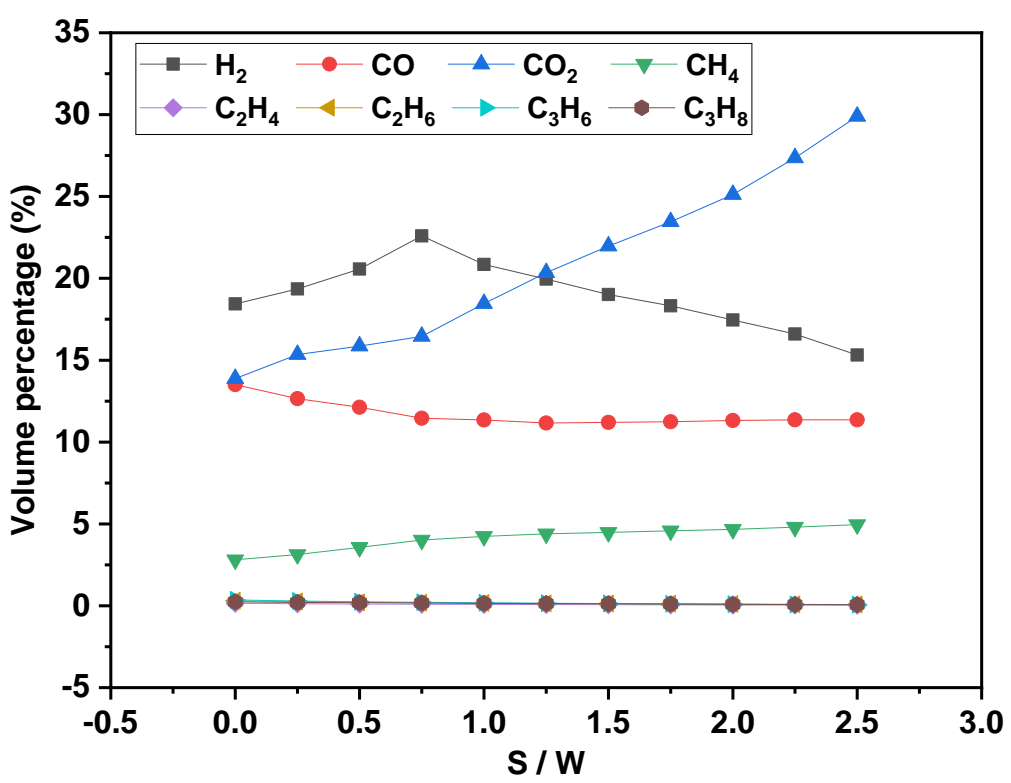

Fig. 9. Yields of the main gaseous product under different $S / W$ values 
Considering the influence of the water content on the gasification process, an ASR pyrolysis and gasification experiment was conducted by controlling the mass ratio of steam to the ASR feedstock $(\mathrm{S} / \mathrm{W})$. The main process parameters of the ASR pyrolysis gasification experiment were set as follows: (1) the pyrolysis temperature was $600{ }^{\circ} \mathrm{C}$, the gasification temperature was $1000{ }^{\circ} \mathrm{C}$, and $\mathrm{ER}=0.25$; (2) the $S / W$ values were $0,0.25,0.5$, $0.75,1.0,1.25,1.5,1.75,2.0,2.25$, and 2.5 . The main gaseous product yields of the ASR pyrolysis and gasification under different $S / W$ values are shown in Fig. 9.

When $S / W$ was in the range of 0 to 0.75 , with an increase in $S / W$, the production of $\mathrm{H}_{2}$ clearly increased, while the production of $\mathrm{CO}$ decreased. This result was mainly due to the influence of the water gas reaction and water vapor conversion reaction. When $S / W$ was greater than $0.75, \mathrm{H}_{2}$ production decreased with an increasing $S / W$, while CO production increased slightly. The main reason was that an excessive water vapor content leads to an increase in the equivalence ratio, and an excessive equivalence ratio would lead to an overall reduction in $\mathrm{H}_{2}$ production according to the analysis results in the previous section. With an increase in $S / W$, the $\mathrm{CO}_{2}$ production increased, and when $S / W$ was greater than 0.75 , the increase in $\mathrm{CO}_{2}$ production was greater, which was mainly because more solid carbon participated in the reaction and finally generated $\mathrm{CO}_{2}$. The $\mathrm{CH}_{4}$ yield increased slightly with an increasing $S / W$, mainly because part of the $\mathrm{H}_{2}$ and $\mathrm{CO}$ participated in methanation reactions. The $\mathrm{C}_{2} \mathrm{H}_{4}, \mathrm{C}_{2} \mathrm{H}_{6}, \mathrm{C}_{3} \mathrm{H}_{6}$, and $\mathrm{C}_{3} \mathrm{H}_{8}$ yields were still small and decreased with an increasing $S / W$. According to the analysis of the gas product distribution under different $S / W$ values, it was helpful to obtain more $\mathrm{H}_{2}$ by adding a certain amount of steam in the ASR pyrolysis and gasification process. The optimal $S / W$ value was 0.75 , and the volume percentages of $\mathrm{H}_{2}, \mathrm{CO}$, and $\mathrm{CO}_{2}$ in the gas products were $22.59 \%, 11.46 \%$, and $16.46 \%$, respectively.

\section{Comparative Study of the Experimental and Simulation Analyses}

Through analyzing and calculating the experimental data of the ASR pyrolysis gasification with and without steam, the experimental results of product yields and the calculated results of evaluation indicators shown in Tables 4 and 5 were obtained. Table 4 mainly shows the distribution of solid, liquid, and gas products obtained from the ASR pyrolysis and gasification process and the evaluation indexes calculated according to formulas 3 through 6 .

Table 4. Results of Pyrolytic Product Distribution and Analysis Parameters

\begin{tabular}{|c|c|c|c|c|c|c|c|c|}
\hline Type & $\mathrm{S} / \mathrm{W}$ & $\begin{array}{c}\text { Solid } \\
(\%)\end{array}$ & $\begin{array}{c}\text { Liquid } \\
(\%)\end{array}$ & $\begin{array}{c}\text { Gas } \\
(\%)\end{array}$ & $\begin{array}{c}Y_{\mathrm{g}} \\
\left(\mathrm{Nm}^{3} / \mathrm{kg}\right)\end{array}$ & $\begin{array}{c}\text { CVRc } \\
(\%)\end{array}$ & $\begin{array}{c}\eta \\
(\%)\end{array}$ & $\begin{array}{c}\text { LHV } \\
\left(\mathrm{MJ}^{3} / \mathrm{Nm}^{3}\right)\end{array}$ \\
\hline Simulation & 0 & 40.56 & 39.68 & 19.76 & 1.64 & 58.69 & 51.80 & 5.52 \\
\hline Experiment & 0 & 48.30 & 36.80 & 14.90 & 1.62 & 50.27 & 45.75 & 4.93 \\
\hline Simulation & 0.75 & 32.46 & 41.35 & 26.19 & 1.67 & 61.12 & 55.77 & 5.84 \\
\hline Experiment & 0.75 & 37.67 & 39.42 & 22.91 & 1.64 & 54.27 & 54.12 & 5.76 \\
\hline
\end{tabular}

Compared with the actual experiment, in the simulation analysis based on the Aspen Plus model, the ASR pyrolysis was more complete, more liquid and gas products were obtained, and the values of CVR,$\eta$ and LHV were higher. This result is attributed to the fact that the reaction environment was more ideal, and most of the reactions proceed immediately as soon as the conditions were met in the simulation process. After steam was introduced, the production changes in the products of the ASR pyrolysis and gasification 
processes in the simulation analysis and the actual experiment were consistent; that is, the solid residue was further reduced, and the liquid product and the gas product further increased.

Table 5 shows the volume percentage of the main small molecule gas products and the values of $Y_{\mathrm{H}_{2}}$ and $\mathrm{H}_{2} / \mathrm{CO}$. After introducing steam, the production of $\mathrm{H}_{2}, \mathrm{CH}_{4}$, and $\mathrm{CO}_{2}$ increased in the simulation analysis and the actual experiment, while the production of other gases decreased. The experimental data verified the reliability of the simulation analysis based on the Aspen Plus model. Therefore, when designing the actual ASR pyrolysis and gasification process, the simulation analysis results based on the Aspen Plus model can be used as a reference to set the pyrolysis temperature, gasification temperature, $\mathrm{ER}, S / W$, and other process parameters, and the gas production trend and LHV value can also be predicted.

Table 5. Results of the Volume Percentage of the Main Small Molecule Gas Products (\%)

\begin{tabular}{|c|c|c|c|c|c|c|c|c|c|c|c|}
\hline Type & $\mathrm{S} / \mathrm{W}$ & $\mathrm{H}_{2}$ & $\mathrm{CO}$ & $\mathrm{CO}_{2}$ & $\mathrm{CH}_{4}$ & $\mathrm{C}_{2} \mathrm{H}_{4}$ & $\mathrm{C}_{2} \mathrm{H}_{6}$ & $\mathrm{C}_{3} \mathrm{H}_{6}$ & $\mathrm{C}_{3} \mathrm{H}_{8}$ & $\mathrm{Y}_{\mathrm{H} 2}$ & $\mathrm{H}_{2} / \mathrm{CO}$ \\
\hline Simulation & 0 & 18.44 & 13.50 & 13.87 & 2.81 & 0.15 & 0.30 & 0.35 & 0.24 & 0.30 & 1.37 \\
\hline Experiment & 0 & 13.48 & 10.15 & 11.74 & 3.59 & 0.27 & 0.28 & 0.37 & 0.26 & 0.22 & 1.33 \\
\hline Simulation & 0.75 & 22.59 & 11.46 & 16.46 & 4.02 & 0.09 & 0.18 & 0.21 & 0.17 & 0.38 & 1.97 \\
\hline Experiment & 0.75 & 17.54 & 9.36 & 13.21 & 5.95 & 0.12 & 0.14 & 0.29 & 0.15 & 0.29 & 1.87 \\
\hline
\end{tabular}

\section{CONCLUSIONS}

1. Aspen Plus simulation software was used to establish a simulation model for the twostage automotive shredder residue (ASR) pyrolysis and gasification process in a fixed bed reactor. In the Aspen Plus simulation analysis process, the pyrolysis temperature was set to $500{ }^{\circ} \mathrm{C}, 600{ }^{\circ} \mathrm{C}, 700{ }^{\circ} \mathrm{C}$, and $800{ }^{\circ} \mathrm{C}$, respectively; the gasifier temperature was set to $800{ }^{\circ} \mathrm{C}, 900{ }^{\circ} \mathrm{C}, 1000^{\circ} \mathrm{C}, 1100{ }^{\circ} \mathrm{C}$, and $1200^{\circ} \mathrm{C}$, respectively. The equivalent ratio (ER) value was varied from 0 to 0.5 . Based on the analysis of the simulation results, the optimal process parameters of the ASR pyrolysis gasification process are determined as follows: the pyrolysis temperature is $600^{\circ} \mathrm{C}$, the gasification temperature is $1000{ }^{\circ} \mathrm{C}, \mathrm{ER}=0.25$, and the ratio of steam to $\operatorname{ASR}(S / W)=0.75$.

2. A two-stage ASR pyrolysis and gasification experimental equipment was established, and a series of comparative experiments under different conditions were conducted. The experimental results verified the accuracy and reliability of the Aspen Plus simulation model for the ASR pyrolysis and gasification process and verified the practical feasibility of the process parameters obtained from the simulation analysis.

3. Through analyzing the changes of evaluation indicators, the two-stage ASR pyrolysis and gasification process designed in this paper can obtain more gas product with higher calorific value. According to the results of $\mathrm{H}_{2} / \mathrm{CO}$ ratio analysis, it is found that the gaseous product is suitable for the subsequent hydrogen production process or FischerTropsch process. 


\section{ACKNOWLEDGMENTS}

The authors express their sincerest thanks to the National Natural Science Foundation of China (http://www.nsfc.gov.cn/) for financing this research within the program "Fundamental Research on Catalytic Gasification of Automobile Shredder Residues (ASR): Mechanism and Its Recovery" under grant number 51675343.

\section{REFERENCES CITED}

Abdelouahed, L., Authier, O., Mauviel, G., Corriou, J. P., Verdier, G., and Dufour, A. (2012). "Detailed modeling of biomass gasification in dual fluidized bed reactors under Aspen Plus," Energy \& Fuels 26(6), 3840-3855. DOI: 10.1021/ef300411k

Acevedo, J. C., Posso, F., Duran, J. M., and Arenas, E. (2018). "Simulation of the gasification process of palm kernel shell using Aspen PLUS," International Meeting on Applied Sciences and Engineering 1126(1), Article ID 012010. DOI: 10.1088/1742-6596/1126/1/012010

Ahmed, A. M. A., Salmiaton, A., Choong, T. S. Y., and Wan Azlina, W. A. K. G. (2015). "Review of kinetic and equilibrium concepts for biomass tar modeling by using Aspen Plus," Renewable and Sustainable Energy Reviews 52, 1623-1644. DOI: 10.1016/j.rser.2015.07.125

Ahmed, N., Wenzel, H., and Hansen, J. B. (2014). "Characterization of shredder residues generated and deposited in Denmark," Waste Management 34(7), 1279-1288. DOI: 10.1016/j.wasman.2014.03.017

Begum, S., Rasul, M. G., and Akbar, D. (2014). "A numerical investigation of municipal solid waste gasification using Aspen Plus," Procedia Engineering 90, 710-717. DOI: 10.1016/j.proeng.2014.11.800

Chen, C., Jin, Y., Yan, J., and Chi, Y. (2010). "Simulation of municipal solid waste gasification for syngas production in fixed bed reactors," Journal of Zhejiang University - Science A: Applied Physics \& Engineering 11(8), 619-628. DOI: 10.1631/jzus.A0900792

Chen, C., Jin, Y., Yan, J., and Chi, Y. (2013). "Simulation of municipal solid waste gasification in two different types of fixed bed reactors," Fuel 103, 58-63. DOI: 10.1016/j.fuel.2011.06.075

Chen, M., and Zhang, F. (2009). "End-of-life vehicle recovery in China: Consideration and innovation following the EU ELV directive," JOM: The Journal of the Minerals, Metals \& Materials Society 61(3), 45-52. DOI: 10.1007/s11837-009-0040-8

Cossu, R., Fiore, S., Lai, T., Luciano, A., Mancini, G., Ruffino, B., Viotti, P., and Zanetti, M. C. (2014). "Review of Italian experience on automotive shredder residue characterization and management," Waste Management 34(10), 1752-1762. DOI: 10.1016/j.wasman.2013.11.014

Cossu, R., and Lai, T. (2015). "Automotive shredder residue (ASR) management: An overview," Waste Management 45, 143-151. DOI: 10.1016/j.wasman.2015.07.042

De Filippis, P., Pochetti, F., Borgianni, C., and Paolucci, M. (2003). "Automobile shredder residue gasification," Waste Management \& Research 21(5), 459-466. DOI: $10.1177 / 0734242 X 0302100508$ 
Deng, N., Li, D., Zhang, Q., Zhang, A., Cai, R., and Zhang, B. (2019). "Simulation analysis of municipal solid waste pyrolysis and gasification based on Aspen Plus," Frontiers in Energy 13(4), 64-70. DOI: 10.1007/s11708-017-0481-7

Doherty, W., Reynolds, A., and Kennedy, D. (2009). "The effect of air preheating in a biomass CFB gasifier using ASPEN Plus simulation,” Biomass and Bioenergy 33(9), 1158-1167. DOI: 10.1016/j.biombioe.2009.05.004

Fiore, S., Ruffino, B., and Zanetti, M. C. (2012). "Automobile shredder residues in Italy: Characterization and valorization opportunities," Waste Management 32(8), 15481559. DOI: $10.1016 /$ j.wasman.2012.03.026

Fu, Z., Zhang, Y., Liu, H., Zhang, B., and Li, B. (2013). "Simulation analysis of biomass gasification in an autothermal gasifier using Aspen Plus," in: Cleaner Combustion and Sustainable World, H. Qi, and B. Zhao (eds.), Springer-Verlag, Berlin, Germany, pp. 479-483. DOI: 10.1007/978-3-642-30445-3_66

Gagliano, A., Nocera, F., Bruno, M., and Cardillo, G. (2017). "Development of an equilibrium-based model of gasification of biomass by Aspen Plus," Energy Procedia 111, 1010-1019. DOI: 10.1016/j.egypro.2017.03.264

Humbird, D., Trendewicz, A., Braun, R. J., and Dutta, A. (2017). “One-dimensional biomass fast pyrolysis model with reaction kinetics integrated in an Aspen Plus biorefinery process model," ACS Sustainable Chemistry \& Engineering 5(3), 24632470. DOI: 10.1021/acssuschemeng.6b02809

Kaushal, P., and Tyagi, R. (2017). "Advanced simulation of biomass gasification in a fluidized bed reactor using ASPEN PLUS," Renewable Energy 101, 629-636. DOI: 10.1016/j.renene.2016.09.011

Lan, W., Chen, G., Zhu, X., Wang, X., Liu, C., and Xu, B. (2018). "Biomass gasificationgas turbine combustion for power generation system model based on ASPEN PLUS," Science of The Total Environment 628-629, 1278-1286. DOI: 10.1016/j.scitotenv.2018.02.159

Lin, K., Chowdhury, S., and Wang, Z. (2010). "Catalytic gasification of automotive shredder residues with hydrogen generation," Journal of Power Sources 195(18), 6016-6023. DOI: 10.1016/j.jpowsour.2010.03.084

Liu, L., Zhao, R., Wang, G., Yang, N., and Wang, D. (2017). "Simulation on pyrolysis gasification of biomass in flue gas based on ASPEN PLUS," Transactions of the Chinese Society for Agricultural Machinery 48(6), 278-283. DOI: 10.6041/j.issn.1000-1298.2017.06.036

Mancini, G., Tamma, R., and Viotti, P. (2010). "Thermal process of fluff: Preliminary tests on a full-scale treatment plant," Waste Management 30(8-9), 1670-1682. DOI: 10.1016/j.wasman.2010.01.037

Naik, K., Shah, K., Bhargava, S., Bankupalli, S., and Parthasarathy, R. (2018). "Oxygensteam gasification of karanja press seed cake: Fixed bed experiments, ASPEN Plus process model development and benchmarking with saw dust, rice husk and sunflower husk," Journal of Environmental Chemical Engineering 6(2), 3061-3069. DOI: 10.1016/j.jece.2018.04.046

Nikoo, M. B., and Mahinpey, N. (2008). "Simulation of biomass gasification in fluidized bed reactor using ASPEN PLUS," Biomass and Bioenergy 32(12), 1245-1254. DOI: 10.1016/j.biombioe.2008.02.020

Niu, M., Huang, Y., Jin, B., and Wang, X. (2013). "Simulation of syngas production from municipal solid waste gasification in a bubbling fluidized bed using Aspen Plus," 
Industrial \& Engineering Chemistry Research 52(42), 14768-14775. DOI:

10.1021/ie400026b

Pala, L. P. R., Wang, Q., Kolb, G., and Hessel, V. (2017). "Steam gasification of biomass with subsequent syngas adjustment using shift reaction for syngas production: An Aspen Plus model," Renewable Energy 101, 484-492. DOI:

10.1016/j.renene.2016.08.069

Passarini, F., Ciacci, L., Santini, A., Vassura, I., and Morselli, L. (2012). "Auto shredder residue LCA: Implications of ASR composition evolution," Journal of Cleaner Production 23(1), 28-36. DOI: 10.1016/j.jclepro.2011.10.028

Pauls, J. H., Mahinpey, N., and Mostafavi, E. (2016). "Simulation of air-steam gasification of woody biomass in a bubbling fluidized bed using Aspen Plus: A comprehensive model including pyrolysis, hydrodynamics and tar production," Biomass and Bioenergy 95, 157-166. DOI: 10.1016/j.biombioe.2016.10.002

Paviet, F., Chazarenc, F., and Tazerout, M. (2009). "Thermo chemical equilibrium modelling of a biomass gasifying process using ASPEN PLUS," International Journal of Chemical Reactor Engineering 7(1), Article Number A40. DOI: 10.2202/1542-6580.2089

Peters, J. F., Banks, S. W., Bridgwater, A. V., and Dufour, J. (2017). "A kinetic reaction model for biomass pyrolysis processes in Aspen Plus," Applied Energy 188, 595-603. DOI: 10.1016/j.apenergy.2016.12.030

Rafati, M., Hashemisohi, A., Wang, L., and Shahbazi, A. (2015). "Sequential modular simulation of hydrodynamics and reaction kinetics in a biomass bubbling fluidizedbed gasifier using Aspen Plus," Energy \& Fuels 29(12), 8261-8272. DOI: 10.1021/acs.energyfuels.5b02097

Ruffino, B., Fiore, S., and Zanetti, M. C. (2014). "Strategies for the enhancement of automobile shredder residues (ASRs) recycling: Results and cost assessment," Waste Management 34(1), 148-155. DOI: 10.1016/j.wasman.2013.09.025

Shaohua, L., Deyong, C., Wenguang, Y., and Haigang, W. (2012). "The effect of ER on biomass gasification in a fixed bed using ASPEN PLUS simulation," World Automation Congress 2012, 1-4.

Shanmughom, R., Chandrasekharan, M., and Palatel, A. (2016). "ASPEN plus modelling of air-steam gasification of biomass with sorbent enabled CO2 capture," ResourceEfficient Technologies 2(2), 94-103. DOI: 10.1016/j.reffit.2016.07.002

Tavares, R., Ramos, A., and Rouboa, A. (2019). "A theoretical study on municipal solid waste plasma gasification," Waste Management 90, 37-45. DOI: 10.1016/j.wasman.2019.03.051

Tungalag, A., Lee, B., Yadav, M., and Akande, O. (2020). "Yield prediction of MSW gasification including minor species through ASPEN plus simulation," Energy 198, Article ID 117296. DOI: 10.1016/j.energy.2020.117296

Vermeulen, I., Van Caneghem, J., Block, C., Baeyens, J., and Vandecasteele, C. (2011). "Automotive shredder residue (ASR): Reviewing its production from end-of-life vehicles (ELVs) and its recycling, energy or chemicals' valorisation," Journal of Hazardous Materials 190(1-3), 8-27. DOI: 10.1016/j.jhazmat.2011.02.088

Wang, L., and Chen, M. (2013). "Policies and perspective on end-of-life vehicles in China," Journal of Cleaner Production 44, 168-176. DOI: 10.1016/j.jclepro.2012.11.036 
Yang, B., and Chen, M. (2020a). "Influence of interactions among polymeric components of automobile shredder residue on the pyrolysis temperature and characterization of pyrolytic products," Polymers 12(8), Article ID 1682. DOI: 10.3390/polym12081682

Yang, B., and Chen, M. (2020b). "Py-FTIR-GC/MS analysis of volatile products of automobile shredder residue pyrolysis," Polymers 12(11), Article ID 2734. DOI: 10.3390/polym 12112734

Article submitted: February 22, 2021; Peer review completed: June 13, 2021; Revised version received: June 13, 2021; Accepted: July 8, 2020: Published: July 13, 2021. DOI: 10.15376/biores.16.3.5964-5984 